\title{
Development, validity and reliability of physical education instructor's personality description scale
}

\author{
Kaprinis Stylianos $^{1}$, Kakkos Vasilios ${ }^{2}$, Strigas Ethan ${ }^{3}$, Kipreos George ${ }^{1}$ \\ ${ }^{1}$ Department of Sport Management, University of Peloponnese, Greece \\ ${ }^{2}$ General Director at Olympic Athletic Center of Athens, Greece \\ ${ }^{3}$ Indiana State University, USA
}

Email address:

skaprinis@yahoo.gr (K. Stylianos), Kipreos@uop.gr (K. George)

\section{To cite this article:}

Kaprinis Stylianos, Kakkos Vasilios, Strigas Ethan, Kipreos George. Development, Validity And Reliability of Physical Education Instructor's Personality Description Scale. American Journal of Applied Psychology. Vol. 3, No. 2, 2014, pp. 39-46. doi: 10.11648/j.ajap.20140302.13

\begin{abstract}
This current study describes the development, reliability and validation of a scale concerning the assessment of Physical Education Instructor's Personality traits. According to the literature review, the Five Factor Model theory (Costa \& McCrae, 1985; 1992; McCrae \& Costa, 1987) is constituted by a widely accepted classification of human characteristics and an integrated description of human personality. For this reason, the questionnaire was structured based on the factors of Extraversion, Agreeableness, Conscientiousness, Emotional stability and lastly on the Openness to new experiences. The questionnaire was distributed to the owners of private health clubs and to the Managers of sports organization municipals who evaluated 481 Physical Education Instructors. During the exploratory factor analysis (n1=161) the criterion of Kaiser-Mayer-Olkin (.946) supported the total sufficiency and suitability of the sample for factor analysis, while the examination of Bartlett's test of Sphericity (2642.791, df 171, p<.00001) led to the rejection of the null hypothesis that variables are independent. The Principal Components Analysis supported the existence of five (5) factors that interpret the $79.539 \%$ of overall variance. During the confirmatory factor analysis (n2=320), was checked the internal consistency with the Cronbach a index which gave: $a=.87$ for the extraversion, $a=.90$ for the agreeableness, $a=.91$ for the conscientiousness, $\mathrm{a}=.82$ for the emotional stability/neuroticism and $\mathrm{a}=.92$ for the openness to experience. The adaptation survey indicators $[\chi 2=$ 535.782, $\mathrm{p}<.001$, Satorra-Bentler $\chi 2=433.245, \mathrm{p}<.001, \mathrm{df} 142, \chi 2 / \mathrm{df}$ ratio $=3.051, \mathrm{NNFI}=.902, \mathrm{CFI}=.919, \mathrm{RCFI}=.903$, $\mathrm{IFI}=.920, \mathrm{SRMR}=.052, \mathrm{RMSEA}=.093(90 \%$ CI of RMSEA =.085-.101) $]$ supported the existence of five correlated factors and exceeded the questionnaire's adaptability limits. Therefore, this specific questionnaire is a sufficient psychometric tool that can be used in the management of human resources in gyms and sports organizations.
\end{abstract}

Keywords: Personality Traits, Five Factor Model, Physical Education Instructors

\section{Introduction}

Human behavior researchers developed for more than decades the personality theory, in search of the personality and the hierarchic structure $[1,13,57,21,18,25,44,41]$. This theory, suggests that there are certain physiological features, explaining the personality stability and the individual differences that differentiate people from each other [48, 58]. These characteristics affect the personal behavior and are able to describe various human manifestations $[3,18,30]$.

Allport \& Odbert [1] were the first researchers who attempted to classify these characteristics. Using the dictionary approach, they recorded 18.000 words which describe the human psyche and personality. Cattell [13] grouped these characteristics firstly into 35 factors and later on, into 16, creating The Sixteen Personality factor Questionnaire (16PF) [14]. Subsequently, many researchers $[57,9,51,24,19,16]$ extensively analyzed the variables and concluded to The Five Personality Dimensions.

Today, the Big Five Personality Dimensions theory is constituted by a widely acceptable human characteristics classification which managed to prevail in the modern literature as one of the most integrated and substantiated human characteristics model [3, 2]. Researchers, estimate that the theoretical Five Factors Model accurately identifies the parameters which forms the human behavior and reveals the aspects of one's personality [18, 44, 33, 42, 45]. There 
are of course, other researchers who deviate from the specific classification and argue about the Big Five Model, suggesting different models. They attempt to cover a range of personalities through a model of six factors [28, 47] or seven dimensions [55], while other researchers consider the five factors more than enough and propose three factors [22, 26].

According to the Five Factors Model, the human personality can adequately be described through five dimensions: a) Extraversion, b) Agreeableness, c) Conscientiousness, d) Emotional Stability- Neuroticism and e) Openness to Experience.

The Extraversion factor refers to the human tendency for social contacts. It evaluates the interpersonal interaction and the human orientation [18, 49]. People with a high level in Extraversion are social, energetic, active and enthusiastic. They keep a positive attitude towards life; they are warm and pleasant people [60].

The Agreeableness factor refers to the human tendency of goodwill and collaboration. This factor evaluates the quality of interpersonal relationships and staff orientation. People with high-level in Agreeableness are benevolent, cooperative, polite and kind-hearted. They add value to develop interpersonal relationships and tend to be altruists, warm and friendly. They also reconcile with their personal "wants" respecting others wishes.

The Conscientiousness factor is related to the consciousness on task, to the commitment on objectives and to the desirable social control of impulse. This factor evaluates the organization level, the stability and the mobilization of a person towards a goal [49]. People with a high-level in Conscientiousness are organized, responsible and reliable. They exhibit a strong focus towards their duties and a commitment on their tasks. Being well-organized and disciplined hard workers, they achieve their goals through a strict planning [60].

The Emotional Stability- Neuroticism factor refers to a person's emotional stability, calmness and the lack of stressful emotions. This factor evaluates the adjustment it identifies the Neuroticism and a large scale of negative emotions such as nervous tension, irascibility, anxiety and depression [17]. People with a high-level in Emotional Stability do not experience often negative emotional states; they are calm, safe and self-satisfied.

Lastly, The Openness to Experience factor refers to the intellectual availability and tendency to derive pleasure from new experiences and ideas. This factor evaluates the activity and constructive search for new experiences. People with high-level in Openness to Experience tend to have a free spirit, a wide range of interests, curiosity and fantasy. They are creative, innovative, and inventive with new original ideas [34].

\subsection{Scope of Research}

The aim of this study is to create a questionnaire concerning the evaluation of Greek Physical Trainer's personality traits working at private gyms and at Municipal
Athletic Organizations. Furthermore, the objective of this current study is to audit the questionnaire's factors structure and reliability, through the exploratory and confirmatory factor analysis.

\subsection{Expediency of Research}

In today's era of intense and tough competition and in a rapidly changing environment, human resources are recognized as an important source of an organization's competitive environment. Organization's effectiveness, productivity and prosperity are based on employee's knowledge, talents and ideas. The organization's ability to evaluate through valid, reliable and objective processes their executive's productivity and to identify inconsistencies of their employee's actual performance to the one desired, contributes to the organization's improvement, strong management, development and profitability. According to the above, it is necessary to study the personal characteristics of physical education instructors, as these characteristics may interpret and affect their job performance.

\subsection{Participants}

In this current study a four hundred eighty one $(N=481)$ Physical Education Instructors Graduates were evaluated, of which 224 were male $(46.6 \%)$ and 257 were female $(53.4 \%)$. Relating to the age of the participants in the study, it ranged from twenty two (22) to fifty two (52) years $(\mathrm{M}=33.1 \mathrm{SD}=$ 7.22) and their work experience from one (1) to twenty (20) years $(\mathrm{M}=8.84 \mathrm{SD}=5.91)$.

During the exploratory factor analysis, the sample was a hundred sixty one $\left(\mathrm{n}_{1}=161\right)$ physical education instructors and during the confirmatory factor analysis the sample was three hundred twenty $\left(\mathrm{n}_{2}=320\right)$ individuals.

\subsection{Data Collection Method}

The questionnaire that was used for this current study is part of a general physical education instructor's job performance evaluation tool. The general evaluation tool is supplemented with professional conduct, cognitive development, leadership, and general and specific performance questionnaires. The purpose of this questionnaire is to record employee's personality characteristics using the Five Factor Model. The questionnaire is consistent by nineteen (19) questions and each question is answered based on Likert's five-point scale, from 1 up to 5, where number 1 corresponds to «Very Poor», number 2 to «Poor», number 3 to «Average», number 4 to «Good» and number 5 to «Very Good» (View Annex).

\subsection{Distribution Process - Data Encoding}

The questionnaires were personally distributed to the owners of the private gyms and to the chairmen/managers of Municipal Athletic Organizations. It was requested from each organization to designate an evaluator who would have direct contact with the personnel and a comprehensive view 
concerning the employee's performance (fitness manager, owner, supervisor, municipal sports programs supervisor, etc.), who would undertake the employees' assessment and complete the questionnaires.

\subsection{Statistical Analysis Methods}

\subsubsection{Factor Analysis Preliminary Verification}

For the verification of the questionnaire's structure and validity, two tests were used, concerning the scale adequacy and the sufficiency of the specific factor analysis sample. Specifically the tests that were used are: (a) Bartlett sphericity test and (b) the KMO criteria concerning the verification of the suitable sample.

\subsubsection{Questionnaire's Structure Validity/Measurement Tools}

The principal component analysis method was chosen for this study, in order to examine the factor, and the questionnaire's validity structure, using the statistical program SPSS. In order to identify the question's factor numbers, main components analysis and factor analysis with Varimax rotation and oblimin rotation were used, to determine the factor's interrelationships [23].

In order to select the Five Factors, the follow criteria's were used: (1) Scree plot test, (2) Eigenvalue - greater -than-one-rule, (3) the interpreted rate variation of each factor, (4) the percentage of the total variation from the exported factors (5) the number of factors that can conceptually be interpreted [46, 56]. Furthermore, the following specific criteria's were used in order the questionnaire's factor structure to be acceptable: (1) Question loadings to the factor, should not be rated more than .40 [54] and (2) each question's communality should be rated more than .30 [37].

\subsubsection{Internal Consistency and Questionnaire's Reliability}

Three methods were used in order to measure the internal consistency and the questionnaire's reliability, concerning the homogeneity of the answers from the measurement tools questions: (a) Cronbach a, (b) Interitem correlation, (c) corrected item - total correlations.

\subsubsection{Confirmatory Factor Analysis}

Confirmatory factor analysis was implemented, in order to study the validation of the measurement tool structure, beyond the exploratory factor analysis. However, prior to the questionnaire's analysis by the confirmatory factor analysis, the distributions of the variables were tested by the following indexes: (a) univariate skewness, (b) univariate kyrtosis, (c) Mardia univariate kyrtosis [39], which specifies the multivariate regularity limits. The univariate kyrtosis index is calculated using the formula $p$ $(p+2)$, where $p$ is the total of the questionnaire's questions. Mardia univariate kyrtosis index should value less than the above equitation. The univariate skewness index and the univariate kyrtosis index, in order for them to be acceptable, their values shouldn't be higher than two (2) and seven (7), respectively, as the higher limits of univariate regularity
[59]. Univariate regularity was tested in order to check if the questions should be conserved or eliminated from the factor analysis. Multivariate regularity was used to identify and select the appropriate factor data analysis method [8, 59].

The following indexes were tested in order to test models fit through the confirmatory factor analysis: (1) $\chi^{2}$ chi square, freedom degrees $\mathrm{df}, \chi^{2 / \mathrm{df}}$ ratio, Satorra Bentler chi- square index $\chi^{2}$ (2) Non- normed fit index, (3) Comparative Fit Index, (4) Robust Comparative Fit index, (5) Incremental Fit index, (6) Standardized Root Mean Squared Residual-SRMR and (7) Root Mean Squared Error of Approximation - RMSEA and the $90 \%$ of RMSEA confidence Interval $[4,7,12,8,29,31,54]$.

The statistic index $\chi^{2}$ is influenced by the sample size, by the freedom degrees as well as by the violation of the normality assumptions. Due to the specific characteristics, many researchers proposed that when evaluating a model, to consider the $\chi 2 / \mathrm{df}$ ratio as a reliable index compared to $\chi 2$ [5]. When the $\chi 2 / \mathrm{df}$ rates are between 2 and 5 , then an acceptable model structure can be supported. When the $\chi 2 /$ df rates are lower than 2 , the model has an impressive data application $[11,36]$.

NNFI, CFI, RCFI and IFI rates could range between 0 and 1 , when the rates are more than .900 they indicate the existence of an acceptable factor structure of the tested model [4]. Hu and Bentler [31] proposed a much stricter criterion for the acceptance of NNFI and CFI indexes, placing the acceptance limit rates to .950. On the other side, when the index rates of SRMR and RMSEA of the tested model are lower than .050 , then the factor structure could be accepted [53, 54]. According to Hu and Bentler [32], the acceptance limit of SRMR index is near .080 and for the RMSEA index is .060, while other researchers identify the best fit limit at the rate of .050 [8, 54]. Furthermore, according to Brown and Cudeck [10], CI; confidence interval of RMSEA should be rated at .050 , in order to support the existence of an acceptable factor structure of the tested model. Lastly, many researchers support that a lower rate than .050 , indicate the existence of a proper fit, while the rates between .050 and .100 note the existence of an acceptable factor structure [40, 50].

According to the results of the exploratory factor analysis, the question loadings and the theoretical structure background of the measuring tools, in order for them to be acceptable, their rates should be higher than .40 , which is an acceptable question loading rate for social sciences [5]. Furthermore, it is worth being noted that the questions from the assessed questionnaires were «allowed» to load only from their factor, where this occurred from the exploratory factor results and the theoretical framework. The question loadings of the other factors were rated at 0.00 , while measurement errors correlation were not permitted. The statistical program EQS 5.7b was used for this current study to research the measurement tools factor structure through the factor analysis [5]. 


\section{Results}

\subsection{Questionnaire's Validation- Exploratory Factor Analysis}

The significant results of Bartlett's sphericity control (2642.791, $d f$ 171, $\mathrm{p}<00001)$ lead to the rejection of the null hypothesis [61] where the variables are independent of each other, while the value of Kaiser-Meyer-Olkin (KMO) criteria which was .946 was at an absolutely satisfactory level [35] supporting the overall adequacy and the suitability of the sample for factor analysis. The basic components analysis based on the factors criteria selection supported that the existence of the pre-mention five factors interprets the $79.539 \%$ of the overall fluctuation (Table 1).The question's loadings and question's communalities, ranged from .357 to .888 and .713 to .838 , respectively. Even though there was a variable in the specific questionnaire, concerning the low loading (0.36), it was eventually preferred to be incorporated into the factor, as it was conceptually considered that it would be able to interpret it [15].

Table 1. Personality Traits Questionnaire's, Question Loadings and Communalities.

\begin{tabular}{|c|c|c|c|c|c|c|}
\hline \multirow{2}{*}{ Questions } & \multicolumn{5}{|c|}{ Question Loadings } & \multirow{2}{*}{$\begin{array}{l}\text { Communali } \\
\text { ties }\end{array}$} \\
\hline & 1 & 2 & 3 & 4 & 5 & \\
\hline 19 & .888 & & & & & .838 \\
\hline 16 & .823 & & & & & .746 \\
\hline 18 & .738 & & & & & .821 \\
\hline 17 & .675 & & & & & .807 \\
\hline 7 & & .861 & & & & .817 \\
\hline 5 & & .792 & & & & .826 \\
\hline 6 & & .790 & & & & .807 \\
\hline 8 & & .689 & & & & .765 \\
\hline 10 & & & .814 & & & .828 \\
\hline 9 & & & .773 & & & .819 \\
\hline 11 & & & .758 & & & .796 \\
\hline 12 & & & .452 & & & .799 \\
\hline 2 & & & & .798 & & .807 \\
\hline 4 & & & & .761 & & .819 \\
\hline 3 & & & & .756 & & .810 \\
\hline 1 & & & & .665 & & .734 \\
\hline 14 & & & & & .861 & .795 \\
\hline 13 & & & & & .644 & .766 \\
\hline 15 & & & & & .357 & .713 \\
\hline $\begin{array}{l}\text { Eigenvalue } \\
\mathrm{S} \\
\%\end{array}$ & 11,305 & 1,360 & ,981 & ,780 & ,686 & \\
\hline $\begin{array}{l}\text { Commun. } \\
\text { Interpret. }\end{array}$ & 59,500 & 7,159 & 5,163 & 4,106 & 3,611 & \\
\hline
\end{tabular}

\subsubsection{Questionnaire's Reliability}

The factor's reliability rates were tested after selecting the final questions based on the questionnaire's main component analysis. The results of the questionnaire's reliability test method are presented in table 2. The indexes were at satisfactory levels, while the Cronbach a rate, as a questionnaire's basic internal consistency index, ranged at a satisfactory level [27, 46, 52]. Furthermore, the correlations of questions with the scale, as well as the correlations of the questions of each factor between them, ranged at absolutely satisfactory levels.

Table 2. Personality Characteristics Questionnaire Reliability Index.

\begin{tabular}{lllll}
\hline $\begin{array}{l}\text { Scale } \\
\text { Questions }\end{array}$ & $\begin{array}{l}\text { Scale } \\
\text { Questions }\end{array}$ & $\begin{array}{l}\text { Correlation } \\
\text { of }\end{array}$ & \\
Correlation & Covariance & $\begin{array}{l}\text { Questions } \\
\text { and scale }\end{array}$ & $A$ \\
Mean & Mean & Mean & \\
Cronbach \\
(Min - & (Min - & (Min - & \\
Max) & Max) & Max) & \\
\hline
\end{tabular}

Extraversion

$\begin{array}{llll}.63 & .49 & .73 \\ (.50-.79) & (.39-.60) & (.65-.82) & .87\end{array}$

Agreeableness

$\begin{array}{llll}.70 & .58 & .79 \\ (.63-.78) & (.58-.59) & (.69-.82) & .90\end{array}$

Conscientiousness

$\begin{array}{llll}.72 & .61 & .80 \\ (.66-.78) & (.53-.75) & (.78-.81) & .91\end{array}$

Emotional stability

$\begin{array}{llll}.60 & .43 & .67 \\ (.59-.61) & (.40-.47) & (.66-.69) & .82\end{array}$

Openness to Experience

$\begin{array}{lll}.75 & .64 \quad .82\end{array}$

$(.67-.81) \quad(.58-.74) \quad(.75-.86) \quad .92$

\subsection{Questionnaire's Validation - Confirmatory Factor Analysis}

The personality characteristics questionnaire is consisted of nineteen (19) questions, of which constituted of the five (5) following factors: (a) Extraversion, (b) Agreeableness (c) Conscientiousness (d) Emotional stability (e) Openness to Experience. The univariate skewness rates, were rated from 1.13 to -0.37 and the univariate kyrtosis rates, were rated from -0.49 to 2.29 , which indicate that the questions have been normally distributed because they haven't exceeded the limits. The limit for univariate skewness is 2 and for the univariate kyrtosis is 7 (West et al., 1995). Mardia univariate kyrtosis indicator, supports the existence of the normalized estimate [normalized estimate $=21.429<19$ $(19+2)]$. For examining the Personality Characteristics Questionnaire's structure, maximum likelihood method was used. 
The personality characteristics questionnaire's adaption indicators supported the existence of the five factors since the confirmatory factor analysis surpassed the questionnaire's adaptation limits. Specifically the adaptation indicators were the following: $\chi^{2}=535.782, p<.001$, Satorra-Bentler $\chi^{2}=433.245, p<.001, d f 142, \chi^{2} / d$ fratio $=$ $3.051, \mathrm{NNFI}=.902, \mathrm{CFI}=.919, \mathrm{RCFI}=.903, \mathrm{IFI}=.920$, SRMR $=.052, \mathrm{RMSEA}=.093(90 \% \mathrm{CI}$ of RMSEA $=.085$ - .101). Particularly, the five factor index test revealed that the index $\chi^{2}$, was a significant statistical element which remarked the existence of sufficient statistical differences between the proposed model and the data index. Nevertheless the other indicators such as NNFI, CFI, RCFI, IFI, SRMR and RMSEA indicated that the proposed model had a proper implementation. The question loadings were satisfactory and were rated from .63 to .92 , while the question errors were rated from .40 to .77 (Shape 1).

Two models were tested, in order to identify the five factors model Personality Characteristics Questionnaire's adequacy. Specifically, the first alternative model included a five factor non-correlated selection, and the second alternative model included a single factor selection, investigating if the tested questionnaire was a single - factor model. According to the results, the five correlated factor model was the one that was suitable (Table 3 ).

Table 3. Personality Characteristics Questionnaire Confirmatory factor analysis: Fit index of three alternative factor structure models.

\begin{tabular}{|c|c|c|c|}
\hline & $\mathrm{FC}_{5}$ & $\mathrm{FNC}_{5}$ & $\mathrm{OF}_{1}$ \\
\hline Fit index & $\begin{array}{l}\text { Five } \\
\text { Correlated } \\
\text { factors }\end{array}$ & $\begin{array}{l}\text { Five } \\
\text { Non- } \\
\text { correlated } \\
\text { factors }\end{array}$ & $\begin{array}{l}\text { One } \\
\text { Factor }\end{array}$ \\
\hline$\chi^{2}$ & 433.245 & 1266.931 & 992.286 \\
\hline$d f$ & 142 & 152 & 152 \\
\hline $\mathrm{p}$ & .001 & .001 & .001 \\
\hline NNFI & .902 & .673 & .732 \\
\hline CFI & .919 & .709 & .762 \\
\hline RCFI & .903 & .628 & .719 \\
\hline IFI & .920 & .628 & .719 \\
\hline SRMR & .052 & .435 & .083 \\
\hline RMSEA & .093 & .171 & .155 \\
\hline $90 \%$ CI of RMSEA & $.085-.101$ & $.163-.178$ & $.147-.162$ \\
\hline
\end{tabular}

Abbreviations:

$\chi^{2}=$ chi square index

$d f=$ freedom degrees,

$N N F I=$ non - normed fit index,

$C F I=$ comparative fit index,

$R C F I=$ robust comparative fit index,

$S R M R=$ standardized root mean square residual,

RMSEA = root mean square error of approximation,

90\% CI of RMSEA $=90 \%$ RMSA Confidence Interval.

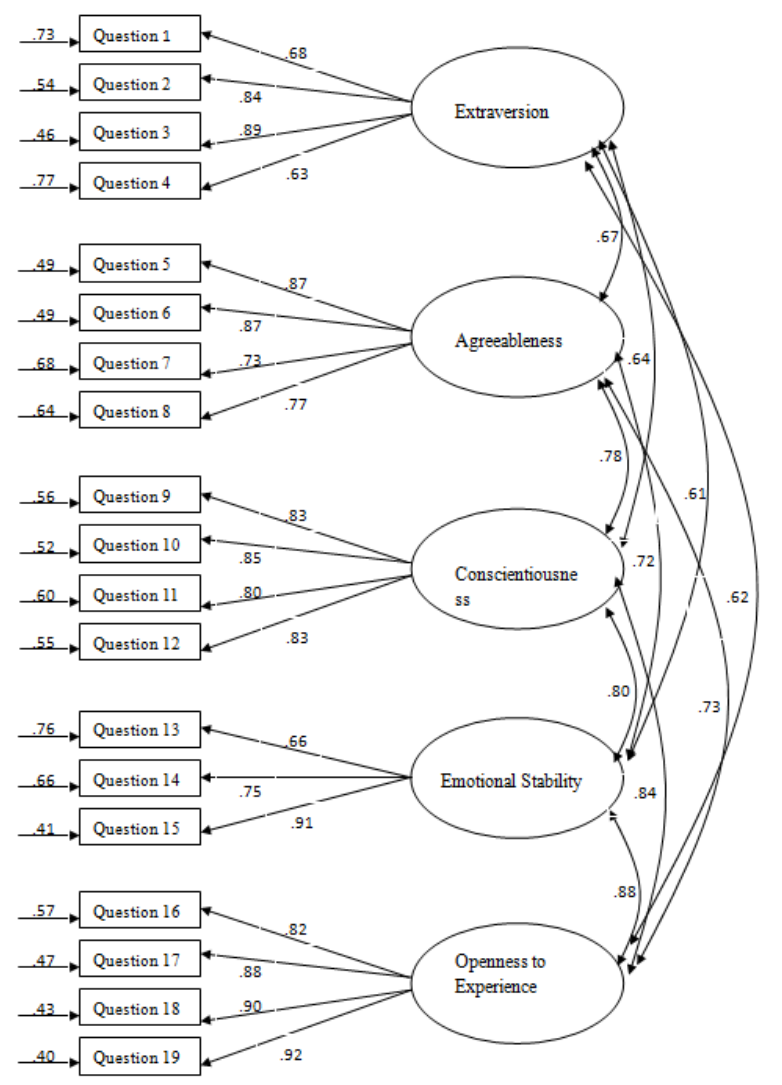

Shape 1. Loadings and question errors of Personality Traits Questionnaire.

\section{Discussion}

This current research aims to study the reliability and the validity of the Physical Education Instructors Personality Traits questionnaire. The questionnaire examines the personality spectrum through the Five Factors Model. The results indicated that the internal consistency coefficients were satisfactory and reliable, while the questionnaire's structure was multi factorial and strongly agreed with the factor theory. According to the theoretical and statistical criteria's, the factor analysis along with the Five Factor selection, interpreted to a sufficient extent the questionnaire's overall variability, and also confirmed its multifactorial structure.

The results of both exploratory and confirmatory factor analysis indicated the existence of the questionnaire's high loadings, noting that the questionnaire is reliable and valid for further research. The reliability results (correlation of questions and factors, Cronbach a) indicated that the questionnaire is reliable since the factor rates were at satisfactory levels.

The questionnaire's statistical analysis indicated the existence of Five Factors. Specifically, the first factor «Extraversion» was consisted of four (4) questions and referred to the employee's tendency to develop social contacts. The second factor «Agreeableness» was consisted of four (4) questions and referred to the employee's tendency of goodwill and collaboration. The third factor «Conscientiousness» was consisted of four (4) questions and 
related to the consciousness on task, to the commitment on objectives and to the desirable social control of impulse. The fourth factor «Emotional Stability/ Neuroticism» was consisted of three (3) questions and referred to the emotional stability, calmness and lack of stressful emotions. Lastly, the fifth factor «Openness to experience» was consisted of four (4) questions and referred to the intellectual availability and tendency to derive pleasure from new experiences and new ideas.

The five factor interrelation supported the positive existence of an important correlation between statistics. Furthermore, this positive correlation provided support to the questionnaire's validity indicating that the five factors investigate the Physical Education Instructor's personality aspects. This gives the opportunity, through an extensive personality characteristics study, to predict and to interpret employee's job performance.

It is advisable, for future studies to examine if job performance is influenced by these five factors. A person's personality is not exclusively characterized by only one factor. A two-dimensional system (such as Extraversion and Conscientiousness) may reveal better the human personality aspect.

In conclusion, the specific questionnaire is a sufficient psychometric tool to be used by human resources administrations and managements of private gymnasiums and athletic organizations.

\section{Annex} Scale

Physical Education Instructors personality description

\begin{tabular}{|c|c|}
\hline & $\begin{array}{lllll}5 & 4 & 3 & 2 & 1 \\
\text { Very } & & & \\
\text { Good } & & & & \text { Vood } \\
\text { Average } & \text { Poor } & \text { Poor } \\
\end{array}$ \\
\hline 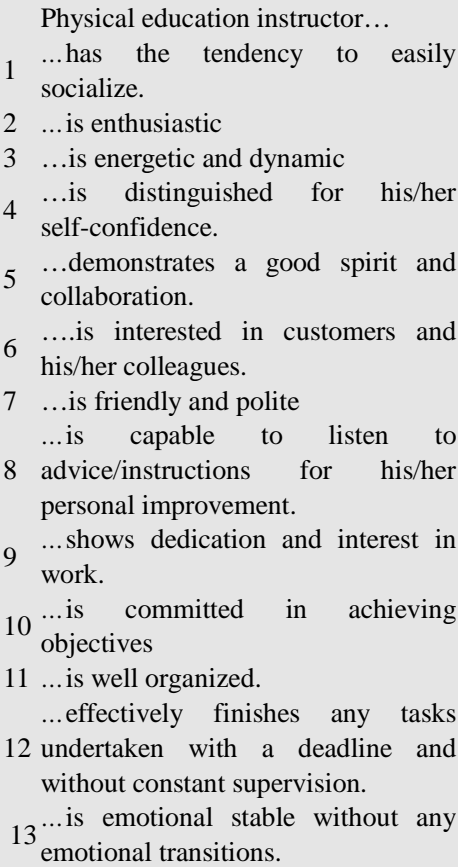 & \\
\hline
\end{tabular}

\begin{tabular}{|c|c|}
\hline & $\begin{array}{lllll}5 & 4 & 3 & 2 & 1 \\
\text { Very } & & & \\
\text { Good } & & & & \text { Vood } \\
\text { Gverage } & \text { Poor } & \text { Poor }\end{array}$ \\
\hline $\begin{array}{l}14 \ldots \text { is self-confident without any } \\
\text { personal conceit. } \\
15 \ldots \text { has determination and a sound } \\
\text { judgment. } \\
16 \ldots \text { can easily adapt changes and } \\
\text { different tasks. } \\
\ldots \text {.can easily anticipate the needs of } \\
17 \text { his/her division and take initiatives } \\
\text { when required. } \\
\ldots \text {.evaluates the issues that occur and } \\
18 \text { handles them with minimum } \\
\text { supervision. } \\
19 . \text { makes the right decisions even } \\
\text { vhen he/she is under pressure. }\end{array}$ & \\
\hline
\end{tabular}

\section{References}

[1] G.W., Allport, and H.S. Odbert, "Trait names: A psycho-lexical study”. Psychological Monographs, (1936), 47, No 211.

[2] M.C., Ashton, and K. Lee, "A theoretical basis for the major dimensions of personality". European Journal of Personality, (2001), 15, 327-353.

[3] R.M., Barrick, and K.M., Mount, "The Big Five Personality Dimensions and Job Performance: A Meta-Analysis", Personnel Psychology, (1991), Vol. 44, pp 1-26.

[4] P.M., Bentler, "Comparative fit indexes in structural models". Psychological Bulletin, (1990), 107, 238-246.

[5] P.M., Bentler, "EQS Structural Equations Program Manual”. Los Angeles, (1995). CA: BMDP Statistical Software.

[6] P. M., Bentler, and D. G. Bonett, "Significance tests and goodness-of-fit in the analysis of covariance structures". Psychological Bulletin, (1980), 88, 588-600.

[7] P.M., Bentler, and C.P. Chou, "Practical issues in structural equation modeling". Sociological Methods and Research, (1987), 16, 78-117.

[8] D.A. Bollen, Structural equations with latent variables. (1989), New York: John Wiley \& Sons.

[9] E.F., Borgatta, "The structure of personality characteristics", Behavioral Science, (1964), 9, 8-17.

[10] M.W., Browne, and R., Cudeck, Alternative ways of assessing model fit. In K.A. Bollen \& J.S. Long (Eds.), Testing structural equation models (pp. 136-162). (1993). Newbury Park, CA: Sage Publications, Inc.

[11] B.M. Byrne, A primer of LISREL: Basic application and programming for confirmatory factor analytic models. (1989). New York: Springer-Verlag.

[12] B. M. Byrne, Structural equation modeling with EQS and EQS/Windows: Basic concepts, applications, and programming. (1994). Thousand Oaks, CA: Sage.

[13] R.B. Cattell, "The description of personality: Basic traits resolved into clusters", Journal of Abnormal and Social Psychology, (1943), 38: 476-506. 
[14] R.B. Cattell, H.W. Eber, and M.M. Tatsuoka, Handbook for the Sixteen Personality Factor Questionnaire, (1970), Champaign, IL: Institute for Personality and Ability Testing.

[15] A.L. Comrey, "The minimum residual method of Factor analysis", Psychological Reports, (1962), 11, 15-18.

[16] P. T. Jr. Costa, R. R. McCrae, and D. A. Dye, "Facet scales for Agreeableness and Conscientiousness: A revision of the NEO Personality Inventory". Personality and Individual Differences, (1991), 12, 887-898

[17] P. T. Jr. Costa, and R. R. McCrae, The NEO Personality Inventory manual. Odessa, FL: Psychological Assessment Resources (1985).

[18] P.T., Jr., Costa, and R.R. McCrae, (1992). Four ways five factors are basic. Personality and Individual Differences, 13, 653-665.

[19] P. T., Jr. Costa, and R. R. McCrae, "Looking backward: Changes in the mean levels of personality traits from 80 to 12". In D. Cervone \& W. Mischel (Eds.), Advances in personality science (2002), (pp. 219 -237).New York: Guilford Press.

[20] Cronbach, L.J. (1951). Coefficient alpha and the internal structure of tests. Psychometrika, 16, 297-334.

[21] H.J. Eysenck and S.B.G. Eysenck Manual of the Eysenck Personality Questionnaire, (1975) Sevenoaks, Kent: Hodder and Stoughton.

[22] H. J. Eysenck, "Four ways five factors are not basic". Personality and Individual Differences, (1992), 13, 667-673.

[23] L.R. Fabrigar, D.T. Wegener, R. C. MacCallum, and E.J. Strahan, "Evaluating the use of exploratory factor analysis in psychological research". Psychological Methods, (1999). 4(3), 272-299.

[24] L. R. Goldberg, "An alternative description of personality: The Big-Five factor structure", Journal of Personality and Social Psychology, (1990), 59, 1216-1229.

[25] L.R. Goldberg, "The structure of phenotypic personality traits". American Psychologist, (1993), 48, 26-34.

[26] H. G. Gough, The California Psychological Inventory administrator's guide. (1987), Palo Alto, CA: Consulting Psychologists Press.

[27] J. F. Hair, R. E. Anderson, R. L. Tatham, and W. C. Black, Multivariate data analysis. (1998), Upper Saddle River, NJ: Prentice-Hall.

[28] R. Hogan, A socio analytic theory of personality. (1983), In M. Page (Ed.) Nebraska symposium on motivation, 1982: Personality--Current theory and research. Lincoln, NE: University of Nebraska Press.

[29] R.H., Hoyle, and A.T. Panter, Writing about structural equation models. In R.H. Hoyle (Eds.), Structural equation modeling: Concepts, issues and applications (1995), (pp. 158-176). Thousand Oaks, CA: Sage.

[30] L.M. Hough, "The big five personality variables—construct confusion: Description versus prediction". Human Performance, (1992), 5: 139-155

[31] L., Hu, and P.M. Bentler, Evaluating model fit. In R.H. Hoyle (Eds.), Structural equation modeling: Concepts, issues and applications (1995), (pp. 76-99). Thousand Oaks, CA: Sage.

[32] L. Hu, and P.M. Bentler, Cutoff criteria for the fit indexes in covariance structure analysis: Conventional criteria versus new alternatives. Structural Equation Modeling, (1999) 6, $1-55$.

[33] O. P. John, The "big five" factor taxonomy: Dimensions of personality in the natural language and in questionnaires. (1990), In L. A. Pervin (Ed.), Handbook of personality theory and research. New York: Guilford.

[34] O. P. John, and S. Srivastava, The Big-Five trait taxonomy: History, measurement, and theoretical perspectives. In L. A. Pervin \& O. P. John (Eds.), Handbook of personality: Theory and research (1999), (Vol. 2, pp. 102-138). New York: Guilford Press.

[35] J.M. Kaiser, "An index of factorial simplicity". Psychometrika, (1974), 39, 31-36.

[36] E.K. Kelloway, Using LISREL for structural equation modeling: A researcher's guide. Thousand Oaks, CA: Sage (1998).

[37] R. Kline, An easy guide to factor analysis. (1994). New York: Routledge.

[38] R.B. Kline, Principles and practice of structural equation modeling. (1998), New York: Guilford Press.

[39] K.V. Mardia, Measures of multivariate skewness and kurtosis with applications. Biometrika, (1970), 57, 519-530.

[40] E. McAuley, T. Duncan, and V. Tammen, "Psychometric properties of the intrinsic motivation inventory in a competitive sport setting: A confirmatory factor analysis". Research Quarterly for Exercise and Sport, (1989), 60 $(48-58)$

[41] R.R. McCrae, NEO-PI-R data from 36 cultures: Further Intercultural comparisons. In R. R. McCrae \& J. Alik. (Eds.), The Five-Factor model of personality across cultures (2002), (pp. 105-125).New York: Kluwer Academic Publisher.

[42] R.R. McCrae, and J. Allik, (Eds.) The Five-Factor Model of personality across cultures. (2002), New York: Kluwer Academic/Plenum Publishers.

[43] R.R. McCrae, and P.T. Costa, "Validation of the five-factor model of personality across instruments and observers", Journal of Personality and Social Psychology, (1987), 52, 81-90.

[44] R. R. McCrae, and O. P. John, "An introduction to the five-factor model and its applications. The five-factor model: Issues and applications". Journal of Personality, (1992), 60, 175-215.

[45] R. R. McCrae, and A. Terracciano, "Personality Profiles of Cultures: Aggregate Personality Traits". Journal of Personality and Social Psychology (2005), 89 (3): 407-425.

[46] J.C. Nunnally, and I.C.H. Bernstein, Psychometric theory (1994), (3rd Ed).New York: McGraw-Hill.

[47] D. Peabody, and L.R. Goldberg, "Some determinants of factor structures from personality-trait descriptors", Journal of Personality and Social Psychology, (1989), 57(3):552-67.

[48] L. A. Pervin, "A critical analysis of current trait theory". Psychological Inquiry, (1994), 5, 103-113. 
[49] L. A., Pervin, and O. P. John, Personality: Theory and research (2001), (8th Ed.). New York: Wiley.

[50] M. T. Rupp, and R. Segal, "Confirmatory factor analysis of a professionalism scale in pharmacy". Journal of Social and Administrative Pharmacy, (1989), 6, 31-38.

[51] G. M. Smith, Usefulness of peer ratings of personality in educational research. Educational and Psychological Measurement, (1967), 27, 967-984.

[52] P. E. Spector, Summated rating scale construction: An Introduction, in Quantitative Applications in the Social Sciences, Sage, Beverly Hills CA. (1992).

[53] J.H. Steinger, "Structural model evaluation and modification: An interval estimation approach". Multivariate Behavioral Research, (1990), 25, 173-180.

[54] B.G., Tabachnick, and L.S. Fidell, Using multivariate statistics. (1996), NY: Harper Collins Publishers Inc.

[55] A., Tellegen, and N. G. Waller, Exploring personality through test construction: Development of the multidimensional personality questionnaire. In S. R. Briggs \& J. M. Cheek (Eds). Personality measures: Development and evaluation.
Greenwich, CT: JAI Press (1993).

[56] Tinsley, H. E. A., \&Tinsley, D. J. (1987).Uses of factor analysis in counseling psychology research. Journal of Consulting Psychology, 27, 561-570.

[57] E.C. Tupes, and R.E. Christall, Recurrent Personality Factors Based on Trait Ratings. Technical Report, Lackland, TX: US Air Force Aeronautical Systems Division (1961).

[58] I., Tsaousis, "Searching the structure of personality: The five factor model". Psychology, (1999), 6 (1) 88-103.

[59] S.G., West, J.F., Finch, and P.J. Curran, Structural equation models with non-normal variables: Problems and remedies. In R.H. Hoyle (Ed.), Structural equation modeling: Concepts, issues, and applications (1995), pp.56-75. Thousand Oaks, CA: Sage.

[60] A.L., Witt, "The Interactive Effects of Extraversion and Conscientiousness on Performance", Journal of Management, (2002), Vol. 28, No 6, pp 835-851.

[61] B. G. Tabachnick, and L. S. Fidell, Using multivariate statistics (2006), (5th ed.) Boston: Allyn and Bacon. 